\title{
Assessing Ethnophysiological Use of Spices and Condiments in Bahir Dar City Market, Bahir Dar, Ethiopia: Ethnophysiological Qualitative Study
}

\author{
Dessalegn Demeke ${ }^{1, *}$, Biruk Getahun ${ }^{1}$, Destaw Mulualem Atinafu ${ }^{2}$ \\ ${ }^{1}$ Department of Biomedical Science (Unit of Physiology), College of Medicine and Health Sciences, Bahir Dar University, Bahir Dar, \\ Ethiopia \\ ${ }^{2}$ Department of Biology, College of Natural and Computational science, Injibara University, Injibara, Ethiopia
}

Email address:

dessalegn140@gmail.com (D. Demeke)

*Corresponding author

To cite this article:

Dessalegn Demeke, Biruk Getahun, Destaw Mulualem Atinafu. Assessing Ethnophysiological Use of Spices and Condiments in Bahir Dar City Market, Bahir Dar, Ethiopia: Ethnophysiological Qualitative Study. Biomedical Sciences. Vol. 6, No. 2, 2020, pp. 25-30.

doi: $10.11648 /$ j.bs.20200602.12

Received: January 28, 2020; Accepted: February 25, 2020; Published: June 15, 2020

\begin{abstract}
Spices and condiments are substances added to foods to enhance aroma and taste. The aim of this study addresses the traditional preparation of spice and condiments and give value for indigenous knowledge in the local society. A community survey was conducted. One hundred sixty-nine informants were selected by using a random sampling technique. Semistructured interviews, observation, in-depth interview and prepared questionnaires were employed to collect pertinent data on the local use of spice and condiments. The data obtained were analyzed by using analytical tools commonly ordered in ethnobiological studies like preference ranking, direct matrix ranking, and pairwise compression. Twenty four species of spice were found in the market. Eight condiments were identified in routinely prepared dishes. From the result of the Paired comparison, Allium sativum scores the highest use-value in the preparation of spice and condiments. The preference ranking result also indicated that Red pepper is the most preferred condiment by the inhabitant of the local community. This study also indicated that the indigenous knowledge in the preparation of spice varies with age groups with the elder more knowledgeable than youngsters. The indigenous knowledge also under threat as the young are not interested in domestic activities. There is knowledge limitation (deterioration) in the younger generation. The younger generation strongly recommends to keep, learn, preserve and maintain their ancestral wisdom for the indigenous use of spice and condiments in the resident.
\end{abstract}

Keywords: Spice, Indigenous Knowledge, Condiment, Ranking, Ethnophysiology

\section{Background}

Spices and food condiments are linked historically, chemically and their physiological effects on human bodies [1-2]. A spice is a dried seed, fruit, root, rhizome, bark or vegetable substance that is characterized as "strongly flavored for the aromatic substance of vegetable origin. Those spices are either used for the preparation of condiments or directly add into foods as a flavoring agent to increase its taste [1-3] and identify the nature of the chemical released as sensory transduction through the nasal cavity or taste buds [3-4]. Spice also functional for those physiological points as an analgesic, anti-inflammatory, anti-malarial, hepatoprotective, antioxidant, antitumor, hypolipidemic and antihelminthic activities of phytochemicals which regulate different body systems [6]. Spices are important for both domestic consumption and export [5].

Condiments are prepared from compounds containing one or more spice [7] extracts to enhance the flavor of the food. Condiments can be both simple (celery salt, garlic salt, onion salt) and compound chili, mitmita, meat sauce, a mint sauce prepared mustard and siljo. Traditionally prepared condiments to give ethnobiological values by using indigenous knowledge [5, 7-8].

Indigenous Knowledge has many applications in law, governance, social work, health and medicine, philosophy, 
education, and the environment. This traditional knowledge emerges from the relationship between human beings and their surroundings and is manifested in acts and practices. This knowledge guides actions, which provide feedback regarding local knowledge in the community, which evolves that the information is transmitted from our ancestral social group to the next generation through the interaction between individuals [9-12].

This study document data related to the ethnophysiological and skill of traditional use of spice and condiments in routinely prepared dish in the study area. The study is the way through which people share their indigenous knowledge as one part of the community to promote the establishment of local and cultural knowledge to create awareness for the younger generation concerning the indigenous use of spice and condiments.

This study also used as a source of information, encouraging, and documenting indigenous knowledge by conducting how the people use spices and condiments traditionally and give more focus on indigenous knowledge to society.

\section{Methods}

\subsection{Study Designs and Data Collection Instruments}

Ethnophysiological community survey design was conducted to assess the use of spices and condiment preparation related to indigenous knowledge in the Bahir Dar city market. The study was conducted in three markets (kebele sixteen, Kebele eleven and kebele four) of the seventeen kebeles market from January 2019 to February 2019. Based on the data of Bahir Dar city administration office Bahir Dar encompasses seventeen kebeles during a time of data collection. Data on indigenous knowledge use for spices and condiments preparation were collected by employing structurally prepared questionnaires, in-depth interviews semistructured interviews and observation. The local preference value of spice and condiments was determined. The local preference value was indicated by the community as the most preferred and the least preferred value of spice and condiments by ranking the spice and condiments commonly used for the preparation of condiments.

\subsection{Study Population}

The source populations were all population in Bahir Dar city. The study population was 169 in the three markets corresponding to the three kebeles (kebele sixteen, Kebele eleven and kebele four) in the age range of 18-60 years. From each market, equal proportion respondents were selected by lottery methods untile the respondent number reaches 169 with equal to the number of sample sizes.

\subsection{Sampling Size and Technique}

Bahir Dar city markets (kebele sixteen, Kebele eleven and kebele four) of the seventeen kebeles were selected for the study purposively because the market is available in this selected kebeles. All the respondents are females and males with an age range of 18-60 years. Population sizes in Bahir Dar city market which use a commercial exchange of spice are approximately 300 , considering a confidence interval of $5 \%$, sample size becomes one hundred sixty-nine [22, 24]. Each respondent' was informed about the objective of the study and the benefit associated with indigenous knowledge commonly used in the community The informants get informed consent and were interviewed by using a random sampling technique until the sample size was saturated.

Through in-depth interviews with the respondents at different levels age range information was obtained concerning spice and condiment preparation in the local community. The trained interviewer also gathers the relevant information related to the condiment preparation context by using a structurally prepared questionnaire to identify the type of spice and condiment prepared and consumed in the local community. A structured questionnaire was prepared in English and translated into Amharic language and was re-translated back to English by linguistic to ensure accuracy and consistency. The entire interview would be held in the Amharic language.

\subsection{Data Analysis}

Data were edited, coded, entered and analyzed by SPSS version 20. Descriptive statistical methods were used to analyze and summarize the inhabitants' sociodemographic characters. Preference ranking, pairwise comparison and direct matrix ranking commonly employed in ethnophysiological research were used to analyze data of spices and condiments preparation associated with indigenous knowledge.

\section{Results}

\subsection{Socio-demographic Information}

Socio-demographic characteristics include, age, sex, educational status were formed based on socio-demographic variables. The contributions devoted to socio-demographic characteristics provide an overview of the available survey (Table 1).

Table 1. Socio-demographic characteristics among inhabitants give responses related to ethnophysiological study in Bahir dar city market, Northwest Ethiopia, 2018. $(n=169)$.

\begin{tabular}{lll}
\hline Variable & Frequency & Percentage (\%) \\
\hline Age in years & & \\
$18-30$ & 53 & 31.36 \\
$31-45$ & 61 & 36.09 \\
$46-60$ & 55 & 32.55 \\
Sex & & \\
Male & 74 & 43.78 \\
Female & 95 & 56.22 \\
Educational status & & \\
Illiterate & 24 & 14.20 \\
Read \&write & 41 & 24.26 \\
Primary education (1-8) & 31 & 18.34 \\
Secondary education (9-12) & 45 & 26.64 \\
Above 12th grade & 28 & 16.56 \\
\hline
\end{tabular}




\subsection{Ethnobiological Use on the Preparation of Spice and Condiments}

The ingredient added to each spice and condiments. In this study, eight condiments were assessed in the local community concerning what kind of spice is added to prepared condiments. Most respondents gave response cross ponding to the condiment with the most important spice added to the prepared condiment (table 2).

Table 2. Indigenous knowledge information base held by the key informants for routinely prepared condiments added to the main dishes.

\begin{tabular}{lll}
\hline No. & Condiments & Spice as Ingredients add to condiment preparation \\
\hline 1 & Mekalesha & Cinnamon, clove, ginger, cardamom, fennel and black pepper \\
2 & Shiro & Fever tea, thyme, rosemary, cardamom, caraway, and fennel. \\
3 & Red pepper & Red pepper, garlic, ginger, cardamom, Basil, fennel, rosemary, thyme \\
4 & Datta & Green chili pepper \\
5 & Mitmita & Garlic, coriander, rosemary, Basil, fennel \\
6 & Bekolt & Bean, garlic, coriander, chilli, onion, garlic \\
7 & Siljo & Black mustard, safflowers, bean flour, salt, fennel, garlic. \\
8 & Nitirkibie & Fever tea, Basil, cardamom, cinnamon, clove, fennel, long pepper, cumin, ginger, garlic, turmeric, fenugreek, \\
\hline
\end{tabular}

\subsection{Comparison of Indigenous Knowledge Vs. Age in Spices and Condiments Preparation}

The use of spice and condiment were indicated (table 3) that it is directly proportional to age increment and indigenous knowledge practice on the local community. In which elders at a higher age and middle age range reflect more spice and condiments use than youngsters. All informants were found in the second and third age groups.
This could have contributed to the identification and association of spices and condiments use knowledge by both second and third age groups as they are more knowledgeable than the people in the first age groups. Furthermore, data collection from the study area by observation and interviews revealed that informants in the first age groups were not conversant enough in providing some ethnobiological information clearly on the used methods of spice and condiments preparation.

Table 3. Spices and condiments use compared by age groups with KAP (Knowledge, Attitude, and Practice).

\begin{tabular}{lll}
\hline Age range & & KAP of informants \\
\hline $1^{\text {st }}$ Age range & $18-30$ & Less KAP \\
$2^{\text {nd }}$ Age range & $31-45$ & Excellent KAP \\
$3^{\text {rd }}$ Age range & $46-60$ & Excellent KAP \\
\hline
\end{tabular}

* KAP=knowledge, Attitude, and Practice.

\subsection{Ranking of Spices and Condiments Based on the Perceived Importance}

\subsubsection{Preference Ranking}

As shown in table 4 below Red peppers, stood first among the sex condiments in the preference ranking methods to know ranks of condiments used in the society. This indicates that the indigenous people through life experience have identified that the best condiments from any other spices that can be used in the same action. The score in the table indicates ranks given to condiments based on this personal preference. The highest number (6) indicates the most preferred and the lowest number (1) the least preferred condiments used in society (Table 4).

Table 4. Preference rankings of condiments used in society.

\begin{tabular}{|c|c|c|c|c|c|c|c|c|}
\hline \multirow{2}{*}{ Condiments } & \multicolumn{6}{|c|}{ Personal preference values of the respondents } & \multirow{2}{*}{ Mean } & \multirow{2}{*}{ Ranking } \\
\hline & 1 & 2 & 3 & 4 & 5 & 6 & & \\
\hline Mekelesha & 25 & 17 & 25 & 30 & 35 & 15 & 86.50 & $5^{\text {th }}$ \\
\hline Silijo & 25 & 17 & 8 & 40 & 23 & 14 & 74.67 & $3^{\text {rd }}$ \\
\hline Red pepper & 12 & 13 & 10 & 40 & 30 & 40 & 103.67 & $1^{\mathrm{st}}$ \\
\hline Mitimita & 5 & 27 & 11 & 16 & 25 & 16 & 62.83 & $6^{\text {th }}$ \\
\hline Datta & 3 & 35 & 19 & 26 & 36 & 25 & 94 & $4^{\text {th }}$ \\
\hline Bekolt & 6 & 12 & 23 & 41 & 25 & 30 & 94.67 & $2^{\text {nd }}$ \\
\hline
\end{tabular}

\subsubsection{Pairedwise Comparison}

For spices that were identified by the informants to be used at their proportions for all values paired comparison was made among the informants to know their ranks. Accordingly,
Allium sativum stood $1^{\text {st }}$ followed by Trigonella foenum graecum. This result indicates that Allium sativum is much favored over other plant spices in the study area (Table 5). 
Table 5. Paired comparison of spices in their proportional use (1=least, $2=$ good, $3=$ very good, $4=$ excellent).

\begin{tabular}{|c|c|c|c|c|c|c|}
\hline \multirow{2}{*}{ Spices } & \multicolumn{4}{|c|}{ Proportional use value } & \multirow{2}{*}{ Mean } & \multirow{2}{*}{ Ranking } \\
\hline & 1 & 2 & 3 & 4 & & \\
\hline Thymus vulgaris & 24 & 30 & 40 & 35 & 86 & $4^{\text {th }}$ \\
\hline Curcuma domestica & 14 & 39 & 27 & 41 & 81.75 & $5^{\text {th }}$ \\
\hline Allium sativum & 10 & 41 & 41 & 42 & 95.75 & $1^{\mathrm{st}}$ \\
\hline Trigonella foenum graecum & 13 & 35 & 38 & 41 & 90.25 & $2^{\text {nd }}$ \\
\hline Capsicum frutescens & 19 & 22 & 36 & 36 & 78.75 & $6^{\text {th }}$ \\
\hline Carum carvi & 21 & 29 & 35 & 33 & 79 & $7^{\text {th }}$ \\
\hline Ocimum bacilicum & 12 & 35 & 39 & 39 & 88.75 & $3^{\text {rd }}$ \\
\hline Sinops alba & 20 & 30 & 25 & 21 & 59.5 & $9^{\text {th }}$ \\
\hline Syzygium aromaticum & 25 & 27 & 20 & 19 & 53.75 & $10^{\text {th }}$ \\
\hline Zingiber officinale & 15 & 33 & 22 & 41 & 77.75 & $8^{\text {th }}$ \\
\hline
\end{tabular}

\subsubsection{Direct Matrix Ranking}

Direct matrix ranking draws explicitly upon multiple dimensions of people perceive after various observations. The result of numerous individuals' responses can be added together to create a matrix that is representative of the community. Alternatively, direct matrix ranking can be done as a group of exercises in which participants reach consensus on the ranking of each item or vote according to their assessments. Ocimum bacilicum is the most important spice in society (Table 6).

Table 6. Different values of spices used in society as $0=$ no use, $1=$ least, $2=$ fair, $3=$ good, $4=$ very good, $5=$ excellent .

\begin{tabular}{llllll}
\hline Use & Curcuma domestica & Allium sativum & Ocimum bacilicum & Thymus vulgaris & Trigonella foenum graecum \\
\hline Color & 5 & 0 & 0 & 0 & 1 \\
Use in meat & 1 & 4 & 5 & 1 & 0 \\
Herbal medicine & 2 & 4 & 3 & 4 & 4 \\
Remembrance & 0 & 3 & 3 & 5 & 4 \\
Ritual & 5 & 1 & 3 & 0 & 1 \\
Smell & 4 & 3 & 5 & 0 & 2 \\
Total & 17 & 15 & 19 & 10 & 12 \\
Ranking & $2^{\text {nd }}$ & $3^{\text {rd }}$ & $1^{\text {st }}$ & $5^{\text {th }}$ & $4^{\text {th }}$ \\
\hline
\end{tabular}

\subsection{Spice Found in the Study Area}

As shown in table 7, the following list of spice was found in the study area available for the preparation of condiments by local inhabitants. (table 7)

Table 7. List of spices used for prepared dishes in the study area.

\begin{tabular}{lll}
\hline Scientific name & Local name & Common name \\
\hline Aframomum corrorima & Korerima & Cardamom \\
Carthamus tinctorius & Suff & Safflower \\
Allium cepa & Key shinkurt & Onion \\
Allium sativum & Nech shinkurt & Garlic \\
Amomum subulatum & Tikur korerima & Black cardamom \\
Brassica nigra & Senafich & Black mustard \\
Bunium persicum & Kemun & Black cumin \\
Capsicum frutescens & Karia & Chili \\
Cinnamomum zeylanicum & Quarafa & Cinnamon \\
Coriandrum sativum & Dimbilal & Coriander \\
Carum carvi & Nech azmud & Caraway \\
Cuminum cyminum & Kemun & Cumin \\
Curcuma domestica & Irid & Turmeric \\
Foeniculum vulgare & Qundoberbere & Fennel \\
Lippia javanica & Koseret & Fever tea \\
Ocimum bacilicum & Besobila & Basil \\
Piper longum & Timiz & Long pepper \\
Pipper nigrum & Tibskitel & Black pepper \\
Rosmarinus officinalis & Tibskitel & Rosemary \\
Sinapis alba & Senafich & Mustard \\
Syzygium aromaticum & Quarafud & Clove \\
Thymus vulgaris & Tosign & Thyme \\
Trigonella foenum graecum & Abish & Fenugreek \\
Zingiber officinale & Jinjibil & Ginger \\
\hline
\end{tabular}




\section{Discussion}

Spice and condiments are unique biologically and culturally. As culturally the indigenous knowledge is an outcome of model-making about the functioning of the natural world that is way all societies, pre-scientific and scientific of knowledge and beliefs handed down through generations by cultural transmission to apply (including humans) with one another and with their environment [8-10]. This study revealed that the indigenous people have also developed different methods for cultural transmission about the relationship of living beings, strive to make sense of how the natural world behaves and by collecting, processing, using and conserving these valuable plants and/or their products. Spices are important for both consumptions with food and commercial value [2]. To obtain optimal health benefits from vegetables and spices, it is suggested that humans should consume a balanced diet with a wide variety of phytochemical sources [3]. The present study revealed one study was done in Nigeria's use of spice and condiments [46].

Modification of culture and increased business work in the area might be playing a major role in changing the attitudes of the younger generation to ignore the use of indigenous knowledge. Linear thinking is important to this concept as easily described as elders pass on, we are losing much indigenous knowledge. It is not that we disagree or we grieve in our own life the passing of our grandparents and greatgrandparents increase the loss of the indigenous knowledge [11-12]. So we strongly keep indigenous knowledge because it improves law, health, agriculture and the natural environment. Cross ponding to this study indigenous knowledge practices is important to control climate change in Ethiopia [16, 25]. One study in Ethiopia also supports spices are important additives to Ethiopian dishes [13]. Ethiopians, in their long history, discovered the medicinal properties of many plants with their provinces had the advantage of recording the information for future generations [14-15, 17]. Other research was also initiated to document indigenous knowledge associated with traditional medicinal plants; specifically to identify the plant parts used for medicinal purposes. Indigenous knowledge also improves Soil and water management [18-20]. After allspice increases food preservation and safety. For example, clove [23] is one of the most valuable spices that has been used for centuries as a food preservative and also black pepper contains antimicrobial compounds that help keep food fresh [21, 23]. Generally, spices are used for flavor, color, aroma, and preservation of food or beverages [7-8].

\section{Conclusion}

There is knowledge limitation (deterioration) in the younger generation due to the existence of diverse cultural, traditional and belief systems. It is strongly recommended that the younger generation keeps to learn, preserve and maintain their ancestral wisdom for the indigenous use of spice and condiments in the resident.

\section{Availability of Data and Materials}

The data used to support the findings of this study are available from the corresponding author upon request

\section{Authors Contributions}

Authors contributed to the concept of the study, the first draft of the paper, the fieldwork, data analysis, and manuscript preparation. The authors also read and approved the final manuscript.

\section{Ethics Approval and Consent Form to Study Participants}

The methods of obtaining ethnobiological data followed guidelines set by the International Society of Ethnobiology Code of Ethics to this research. Prior to this oral and written informed consent was obtained from all study participants [26]. No ethical committee permits were required.

\section{Competing Interests}

The authors declare no conflict of interest.

\section{Funding}

No funding sources.

\section{Acknowledgements}

My special gratitude goes to all the study participants who wanted to share their indigenous knowledge.

\section{References}

[1] Singh KMP, Singh D. Performance of coriander, fenugreek, and soya as intercrop under gladiolus based intercropping system. Journal of Agri Search. 2014; 1 (4): 246-50.

[2] Siruguri V, Bhat RV. Assessing intake of spices by pattern of spice use, frequency of consumption and portion size of spices consumed from routinely prepared dishes in southern India. Nutrition journal. 2015; 14 (1): 7.

[3] Green B, Nworgu F, Obazee M. Spices and food condiments in Niger-Delta region of Nigeria. African Journal of Biotechnology. 2012; 11 (79): 14468-73.

[4] Ndukwu B, Ben-Nwadibia N. Ethnomedicinal aspects of plants used as spices and condiments in the Niger delta area of Nigeria. Ethnobotanical Leaflets. 2005; 2005 (1): 10.

[5] Panda H. Handbook on spices and condiments (cultivation, processing and extraction): ASIA PACIFIC BUSINESS PRESS Inc.; 2010. 
[6] Hui-Lin L. The origin of cultivated plants in Southeast Asia. Economic Botany. 1970; 24 (1): 3-19.

[7] Darriet A. Herbs, spices and essential oils. Handbook of food products manufacturing Wiley, New York. 2007: 205-20.

[8] Albuquerque UP, Alves RRN. Introduction to ethnobiology: Springer; 2016.

[9] Albuquerque UP, De Medeiros PM, Casas A. Evolutionary ethnobiology. Evolutionary ethnobiology: Springer; 2015. p. $1-5$.

[10] Gadgil M, Berkes F, Folke C. Indigenous knowledge for biodiversity conservation. Ambio. 1993: 151-6.

[11] McGregor D. Coming full circle: Indigenous knowledge, environment, and our future. American Indian Quarterly. 2004; 28 (3/4): $385-410$.

[12] DeWalt BR. Using indigenous knowledge to improve agriculture and natural resource management. Human organization. 1994: 123-31.

[13] Tesfa T, Bayu W, Gashaw A, Beshir H. Spice Production, Marketing, and Utilization in South Wollo, Ethiopia. East African Journal of Sciences. 2017 Oct 16; 11 (1): 27-36.

[14] Sumner C, Yimam W. Indigenous Knowledge Systems in Ethiopia Report of Ethiopia National Workshop.

[15] Idris, Tetemke Mehari, Mogessie Ashenafi A. Some microbiological and biochemical studies on the fermentation of 'awaze'and' datta', traditional Ethiopian condiments. International journal of food sciences and nutrition. 2001 Jan $1 ; 52$ (1): 5-14.

[16] Hadgu KM, Gebremichael D. Indigenous knowledge practices for climate change adaptation and impact mitigation: The case of smallholder farmers in Tigray, Northern Ethiopia.

[17] Jansen PC. Spices, condiments and medicinal plants in Ethiopia, their taxonomy and agricultural significance. Pudoc; 1981.
[18] Yirga G. Assessment of indigenous knowledge of medicinal plants in Central Zone of Tigray, Northern Ethiopia. African Journal of Plant Science. 2010 Jan 31; 4 (1): 006-11.

[19] Erkossa T, Ayele G. Indigenous knowledge and practices for soil and water management in East Wollega, Ethiopia. In Conference on International Agricultural Research for Development, Deutscher Tropentag Göttingen, October 2003 Oct 8 (pp. 8-10).

[20] Meaton J, Abebe B, Wood AP. Forest spice development: The use of value chain analysis to identify opportunities for the sustainable development of Ethiopian Cardamom (Korerima). Sustainable development. 2015 Jan; 23 (1): 1-5.

[21] Gottardi D, Bukvicki D, Prasad S, Tyagi AK. Beneficial effects of spices in food preservation and safety. Frontiers in microbiology. 2016 Sep 21; 7: 1394.

[22] Araújo TA, Almeida AL, Melo JG, Medeiros MF, Ramos MA, Silva RR, Almeida CF, Albuquerque UP. A new technique for testing distribution of knowledge and to estimate sampling sufficiency in ethnobiology studies. Journal of Ethnobiology and Ethnomedicine. 2012 Dec; 8 (1): 11.

[23] Vandebroek I. Cultural comparisons in ethnobiological research. In Introduction to Ethnobiology 2016 (pp. 265-271). Springer, Cham.

[24] da Silva TC, Cruz MP, de Sousa Araújo TA, Schwarz ML, Albuquerque UP. Methods in research of environmental perception. In Methods and techniques in ethnobiology and ethnoecology 2014 (pp. 99-109). Humana Press, New York, NY.

[25] Riffel AD, Luckay M. Views on Indigenous Knowledge Questionnaire (VIKQ) on the beliefs on weather prediction in the Western Cape, South Africa.

[26] Hardison P, Bannister K. Ethics in ethnobiology: history, international law and policy, and contemporary issues. Ethnobiology, edited by EN Anderson, DM Pearsall, ES Hunn, and NJ Turner. 2011 Jul 18: 27-49. 